\title{
Coordinated Air Conditioning Resources Scheduling with High Photovoltaic Penetrations
}

\author{
Xueqing $\mathrm{Wu}^{1}$, Runji $\mathrm{Wu}^{2}$, Dongxiao Wang ${ }^{2}$, Jinxiao Wei ${ }^{1}$, Xuecong $\mathrm{Li}^{2}$, Loi Lei Lai ${ }^{2}$, Chun Sing Lai ${ }^{3}$ \\ 1. Guangdong Foshan Power Construction Corporation Group Co., Ltd, Foshan, China \\ 2. School of Automation, Guangdong University of Technology, Guangzhou, China \\ 3. School of Civil Engineering, University of Leeds, UK
}

\begin{abstract}
Controllable air conditioning loads (ACLs) and distributed renewable energy sources have become one of the research focuses in recent decades. This paper aims to propose a new control strategy which can schedule the interruptible ACLs and increase the photovoltaic (PV) penetration rate in distribution network, with battery energy storage system (BESS) involved in the scheduling process. The control scheme is modelled and further transformed into a MILP (mixed integer linear programming) problem whose objective function is to minimise the system operation costs. In order to guarantee the thermal comfort of customers, an advanced two-parameter thermal model is applied to describe the indoor thermodynamic transition more accurately. The proposed scheme is tested on a five-node radial distribution network based on large-scale integrated commercial buildings. The simulation results demonstrate the efficiency of proposed control scheme.
\end{abstract}

Index Terms-Air conditioning loads, mixed integer linear programming, demand side management, photovoltaic penetrations

\section{NOMENCLATURE}

$\begin{array}{ll}\text { Abbreviations } \\ \text { AC } & \text { Air conditioner } \\ \text { ACL } & \text { Air-conditioning load } \\ \text { BESS } & \text { Battery energy storage system } \\ \text { DMS } & \text { Distribution management system } \\ \text { DSM } & \text { Demand side management } \\ \text { ESS } & \text { Energy storage system } \\ \text { LC } & \text { Load controllers } \\ \text { MC } & \text { Micro source controllers } \\ \text { MGCC } & \text { Micro grid control center } \\ \text { PV } & \text { Photovoltaic } \\ \text { SOC } & \text { State of charge } \\ \text { Parameters } & \\ C O P & \text { Coefficient of performance of air-conditioner } \\ C p_{a} & \text { Heat capacity of the air, } \mathrm{J} / \mathrm{kg} \cdot{ }^{\circ} \mathrm{C} \\ C p_{w} & \text { Heat capacity of the wall, } \mathrm{J} / \mathrm{kg} \cdot{ }^{\circ} \mathrm{C} \\ C_{b u y i}(t) & \text { Electricity purchase price at node } i \text { at time } t, \\ C_{\text {selli }}(t) & \text { Y } / \mathrm{kWh} \\ & \text { Electricity selling price at node } i \text { at time } t\end{array}$

$G \quad$ Solar irradiation forecast, $\mathrm{W} / \mathrm{m}^{2}$

$G \quad$ Solar irradiation in the standard environment, set as $1000 \mathrm{~W} / \mathrm{m}^{2}$

$M_{a} \quad$ Mass of indoor air, $\mathrm{kg}$

$M_{w} \quad$ Mass of house walls, $\mathrm{kg}$

$P_{a c} \quad$ Rated power of air conditioner, $\mathrm{kW}$

$P_{b a t}(t) \quad$ Power flow from battery to consumers at time

$P_{b a t}(t) \quad t, \mathrm{~kW}$

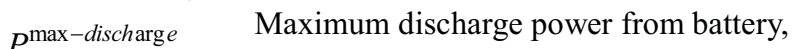
bat $\mathrm{kW}$

$P_{g \text { buyi }}(t) \quad$ The amount of power bought from external

grid at node $i$ at time $t, \mathrm{~kW}$

$P_{g_{-} \text {selli }}(t)$ The amount of power sold to external grid at

$P_{g_{-} b u y}(t) \quad$ Power bought from grid at time $t, \mathrm{~kW}$

$P_{g_{-} \text {sell }}(t) \quad$ Power sold to the grid at time $t, \mathrm{~kW}$

$P_{g \max } \quad$ Maximum grid power capacity, $\mathrm{kW}$

$P_{S r} \quad$ Equivalent rated output power of photovoltaic panels, $\mathrm{kW}$

$P_{\text {uncontro_load }}(t) \quad$ Uncontrollable load at time $t, \mathrm{~kW}$

$Q_{a c} \quad$ Air conditioner cooling energy, J

$Q_{\text {gain_a }} \quad$ Heat gain from ambient to indoor air, J

$Q_{\text {gain_w }} \quad$ Heat gain from ambient to the wall, J

$Q_{\text {ex }} \quad$ Heat exchange between indoor air and indoor

walls, $\mathrm{J}$

$R_{c} \quad$ A certain irradiation point, set as $150 \mathrm{~W} / \mathrm{m}^{2}$

$R_{e q} \quad$ House envelope equivalent thermal resistance

$R_{w a} \quad$ Equivalent thermal resistance between the ambient and wall outer surface

$R_{w r} \quad$ Equivalent thermal resistance between house

indoor air and wall inner surface

$S_{a c}(t) \quad$ Operation status of air conditioners at time $t$

$\tau \quad$ Time step during which the parameters are

assumed as constants

$T_{\text {amb }}(t) \quad$ Ambient temperature at time $t,{ }^{\circ} \mathrm{C}$

$T_{r}(t) \quad$ Indoor air temperature at time $t,{ }^{\circ} \mathrm{C}$ 


$\begin{array}{ll}T_{r}^{\min } & \text { Lower limit of indoor air temperature, }{ }^{\circ} \mathrm{C} \\ T_{r}^{\max } & \text { Upper limit of indoor air temperature, }{ }^{\circ} \mathrm{C} \\ T_{w}(t) & \text { Wall temperature at time } \mathrm{t},{ }^{\circ} \mathrm{C} \\ T_{w}^{\min } & \text { Lower limit of wall temperature, }{ }^{\circ} \mathrm{C} \\ T_{w}^{\max } & \text { Upper limit of wall temperature, }{ }^{\circ} \mathrm{C}\end{array}$

\section{INTRODUCTION}

With the development of smart grids, the amount of air conditioning loads (ACLs) in distribution network is gradually increasing, which leads to short-term but sharp peak electricity demands, especially in hot summer days. In the meantime, due to the buffering capacity of air-conditioned buildings, they have unique thermal storage characteristic, which allows ACLs to participate in demand side management (DSM) schemes.

In addition to this, distributed renewable energy sources are playing an increasingly important role in distribution networks [1]. One of the most promising renewable energy generation techniques is solar photovoltaic (PV) power, which has been widely used in recent decades [2]. However, as natural characteristics of solar PV, variability and randomness have negative impacts on power system operation, which limits PV generation utilization rate to some extent [3].

Researchers have put forward many DSM schemes by utilizing ACLs and made great efforts to improve PV generation level in the system. In [4], the authors propose a novel supply-based feedback control strategy to optimize demand response control of air-conditioning loads. In [5], a direct load control model is built for scheduling ACLs, which adopts an International Organization of Standard thermal comfort model and proposes a fuzzy adaptive imperialist competitive algorithm. In [6], the authors build a highly accurate aggregated model for large-scale ACLs and design a new control method under realistic conditions.

As for improving renewable penetration rate, in [7], the authors model thermostatic loads using a novel bilinear partial differential equation framework and a sliding mode controller, showing the potential for accommodating ACLs to wind power generation. In [8], a coordinated control scheme of distributed energy storage system (ESS) is put forward to solve the voltage problem caused by high PV penetration in low-voltage distribution network. In [9], the authors employ smart transformers to reduce voltage issues caused by high penetration of PV generation and electric vehicles in low voltage distribution networks. In [10], a new droop control is used in ESS dispatch commands generation, which can increase PV penetration through optimizing the ESS placement and sizing. In [11], the authors aim to enhance the PV utilization level by applying a hybrid model consisting of wavelet transform and neural networks to forecast the solar energy.

By reviewing the literature, the authors find that many of the existing works focus on formulating control strategy for
ACLs solely through some new control tactics and models. On the other hand, these works try to improve the penetration level of PV generation by optimizing the design and control of ESSs or using smart electrical equipment. Few of them attempt to establish an accurate ACL model to adapt the intermittent renewable energy generation, especially the ACLs and PV panels installed in large-scale commercial buildings. To close the research gap, this paper aims to propose a coordinated control scheme for controllable ACLs, PV generation systems and battery energy storage systems (BESSs), which can minimize system operation cost while reducing peak load of the power grid and improving PV generation penetration level. The control scheme is modelled and further transformed into a MILP (mixed integer linear programming) problem whose objective function is to minimise the system operation costs. To guarantee the thermal comfort of customers, an advanced two-parameter thermal model is applied to demonstrate the indoor thermodynamic transition process more accurately.

The paper is organized as follows. After the introduction, Section II presents the components modeling. Section III introduces the proposed MILP model. In section IV, a case study is performed and simulation results are analyzed. Section V draws a conclusion.

\section{COMPONENTS MODELING}

\section{A. ACLs}

In order to use the thermal inertia of ACL groups to accommodate the intermittent renewables in distribution network, while satisfying the end users' thermal comfort, it is necessary to fully comprehend the dynamic thermal behavior of air-conditioned buildings. Many thermal models have been proposed to describe the thermal process [12]. Here we compare two kinds of models, shown in Fig. 1. Oneparameter thermal model, shown in Fig. 1(a), only considers thermal resistance and neglects any thermal capacitance. The heat exchange between the building and the ambient environment is assumed to be only related to indoor and outdoor temperature difference. A thermal transient phenomenon will happen and reach a final equilibrium state following the working of air-conditioners [13]. A twoparameter thermal model is shown in Fig. 1(b) [14]. Different from one-parameter thermal model, the capacitance between walls and internal/ambient air is considered in this model. Therefore, the thermal process is composed of two parts, indoor thermal mass and the walls' thermal mass. According to [15], the complexity of thermal model can impact the accuracy when calculating the cooling load. As a consequence, the more accurate two-parameter model is chosen in this paper, with dynamic process being explained below: 

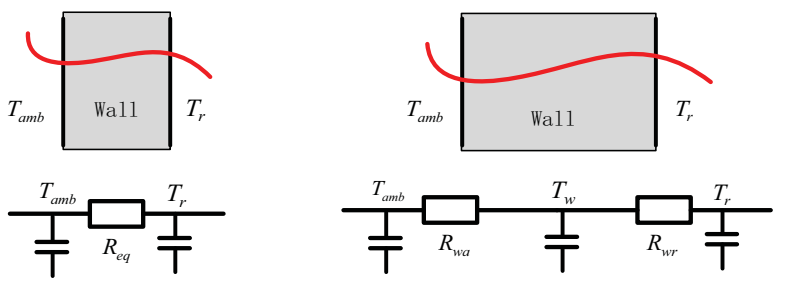

Fig. 1. Schematic of thermal models: (a) One-parameter model (b) Two-parameter model

$$
\begin{gathered}
\frac{d T_{r}(t)}{d t}=\frac{1}{M_{a} \times C p_{a}}\left[\frac{d Q_{\text {gain_a }}(t)}{d t}-\frac{d Q_{e x_{-} w_{-} r}(t)}{d t}-\frac{d Q(t)}{d t}\right] \\
\frac{d T_{w}(t)}{d t}=\frac{1}{M_{w} \times C p_{w}}\left[\frac{d Q_{\text {gain_w }}(t)}{d t}+\frac{d Q_{e x_{-} w_{-} r}(t)}{d t}\right] \\
\frac{d Q_{\text {gain_a }}(t)}{d t}=\frac{T_{a m b}-T_{r}}{\mathrm{R}_{e q}} \\
\frac{d Q_{e x_{-} w_{-} r}(t)}{d t}=\frac{T_{w}-T_{r}}{R_{w r}} \\
\frac{d Q_{a c}(t)}{d t}=C O P \times P_{a c} \\
\frac{d Q_{\text {gain_w }}(t)}{d t}=\frac{T_{a m b}-T_{w}}{R_{w a}}
\end{gathered}
$$

Equations (1) and (2) show the temperature change rates of indoor air and wall. Equations (3)-(6) refer to the heat gain change rate from the ambient to the indoor air, heat gain change rate between walls and indoor air, air-conditioners cooling energy change rate, and heat gain change rate form the ambient to the walls.

This paper splits the overall operation time period ${ }^{t}$, which refers to 24 hours, into $\mathrm{N}$ time steps. When $\mathrm{N}$ is large enough, the thermal dynamic model can be linearized as follows:

$$
\begin{array}{r}
T_{r}(t)=\left(1-\frac{1}{M_{a} \times C p_{a} \times R_{e q}}\right) \times T_{r}(t-1) \\
\quad+\frac{1}{M_{a} \times C p_{a} \times R_{e q}} \times T_{a m b}(t-1)+\frac{T_{w}(t-1)-T_{r}(t-1)}{M_{a} \times C p_{a} \times R_{w r}} \\
-S_{a c}(t) \times \frac{Q_{a c}(t-1)}{M_{a} \times C p_{a}}, \forall t \in[2, N] \\
T_{w}(t)=T_{w}(t-1)+\frac{T_{a m b}(t-1)-T_{w}(t-1)}{M_{w} \times C p_{w} \times R_{w a}}+ \\
\frac{T_{r}(t-1)-T_{w}(t-1)}{M_{w} \times C p_{w} \times R_{w r}}, \forall t \in[2, N]
\end{array}
$$

generation groups is one of our targets. The output power of PV groups mainly depends on the solar irradiation rate. According to [16], in general, generated power is proportional to the square of solar radiation until it reaches a certain irradiation point. After that, the generation amount would be proportional to a certain value. The solar PV power generation model is given in Eq. (9):

$$
P_{S}(G)=\left\{\begin{array}{l}
P_{S r}\left(\frac{G^{2}}{G_{s t d} R_{c}}\right), \text { for } 0<G<R_{c} \\
P_{S r}\left(\frac{G}{G_{s t d}}\right), \text { for } G>R_{c}
\end{array}\right.
$$

\section{BESSS}

According to [17], the BESS model is given below, considering the state of charge (SOC) limits and rated power of BESS.

$$
\begin{gathered}
\operatorname{SoC}(t)=\frac{\left(P_{w}(t-1)-P_{b a t}(t-1)-P_{g_{-} \text {sell }}(t-1)\right) \cdot n_{\text {effi }} \cdot \tau}{E_{\text {BESS }}} \\
+\operatorname{SoC}(t-1) \\
0 \leq \operatorname{SoC}(t) \leq 1 \\
0 \leq P_{b a t}(t) \leq P_{\text {bat }}^{\text {max discharge }}
\end{gathered}
$$

\section{PROPOSED MILP MODEL}

The control scheme in this paper can be formulated as a MILP problem. This section describes the proposed MILP model, including objective function and system constrains. Fig. 2 gives a simplified system network structure. Given the feed-in-tariff of PV generation is lower than the electricity retail price in the tested network, consuming the local renewable energy as much as possible is more advantageous. In order to smooth the PV power output, a BESS is configured between the PV panels and local loads. This paper assumes that there is no direct power flow from the external grid to the batteries. When the system demand is at a relatively low level, the BESS would sell remaining power to the external grid. When the BESS cannot support the end users, the system needs to purchase electricity from the grid. All devices in this network are managed by a Micro Grid Control Center (MGCC) and more details will be given in Case Study Section.

\section{B. $P V S$}

Making full use of the power provided by solar PV power 


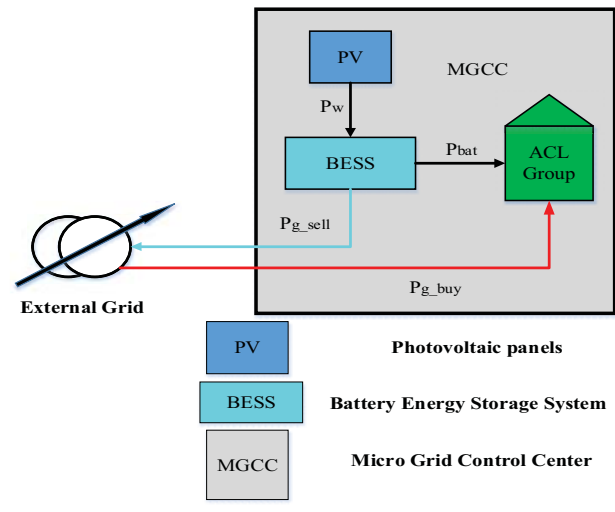

Fig. 2 Simplified system network structure

\section{A. Objective Function}

Consuming power from local PV cells as much as possible can improve the utilization of PV generation. At the same time, it can directly reduce the power that customers purchase from the external power grid, which will reduce the supply burden on the external grid to some extent. The goal of the operation system is to minimize the total operating cost, while satisfying relevant constraints. The net cost of the distribution network depends on the real-time power transmission between the demand side and the external power grid, as well as the electricity retail price. Therefore, the objective function is formulated as Eq. (13), aiming to minimize the total operating cost over the entire time period of operation and for all nodes of the system.

$$
\min \sum_{t=1}^{N} \sum_{i=1}^{N}\left(P_{g_{-} \text {buyi }}(t) \times C_{\text {buyi }}(t)-P_{g_{-} \text {selli }}(t) \times C_{\text {selli }}(t)\right) \cdot \tau
$$

It should be noted that the decision variables of the objective function are $P_{g_{-} b r y i}(t)$ and $P_{g_{-} \text {selli }}(t)$, which are time varying and determine the net cost.

\section{B. Constraints}

Objective function (13) is subject to the following three constraints.

\section{a. Load Balance Constraints}

In normal operation, the power flow between the distribution network and the external power grid must be balanced. That is, the sum of the uncontrollable load and ACLs must be equal to the sum of the BESS discharge power and the power purchased by the external grid. At the same time, the amount of electricity purchased from the grid cannot exceed the maximum capacity limit of the distribution network. In addition, the amount of electricity sold to the grid must not exceed the maximum capacity of the BESS. The above constraints are formulated and expressed as Equations (14)-(16) below:

$$
P_{\text {uncontro_load }}(t)+P_{a c} \times S_{a c}(t)=P_{b a t}(t)+P_{g_{-} b u y}(t)
$$

$$
\begin{aligned}
& 0 \leq P_{g_{-} \text {sell }}(t) \leq P_{\text {bat }}^{\max \text { discharge }} \\
& 0 \leq P_{g_{-} b u y}(t) \leq P_{g \max }
\end{aligned}
$$

\section{b. Thermal Comfort Constraints}

Ensuring the end users' thermal comfort is an essential prerequisite of adding ACLs to DSM through direct load control technique. The thermal comfort constraint is expressed by Eq. (17), while the wall temperature range is given by Eq. (18). The operation status of air conditioners is represented by a binary function shown in (19), where $S_{a c}$ $=1$ means the ACs are ON and $S_{a c}=0$ means OFF. This paper assumed that ACs work at rated power once turned on.

$$
\begin{aligned}
& T_{r}^{\min } \leq T_{r}(t) \leq T_{r}^{\max } \\
& T_{w}^{\min } \leq T_{w}(t) \leq T_{w}^{\max } \\
& S_{a c}(t)= \begin{cases}1, & O N \\
0, & O F F\end{cases}
\end{aligned}
$$

\section{c. PVs and BESSs constraints}

The operational constraints of PV and BESS are specified in (9)-(12).

\section{CASE STUDY}

\section{A. Experimental Setup}

Guangdong Fudian Data Center, located in Foshan City, Guangdong Province, is formed by many Internet Data Center buildings and integrated commercial buildings which are equipped with a lot of air conditioners. This paper selects part of the commercial buildings for research. The case study is based on a five-node radial distribution network with solar $\mathrm{PV}$ power generation groups and Li-ion battery groups. The network configuration of the system is shown in Fig. 3. There are many ACLs in each node. All ACLs of each group are aggregated and controlled by Controllable Load Controllers (LC). PV panels and Li-Ion battery packs are aggregated and controlled by Micro Source Controllers (MC). All MCs and LCs in this system are connected to the MGCC for further management.The MGCC exchanges information with upper layer Distribution Management System (DMS). The rated capacity of solar PV power generation system and Li-Ion battery packs are shown in Table 1. The system model proposed in this paper is implemented by MATLAB software combined with MOSEK toolbox [17]. The simulation is executed on a DELL desktop with an Intel Core i5-6500 4cores CPU (3.20GHz, 3.19GHz) and 8.00GB RAM and a 64bit Windows 10 operating system. 


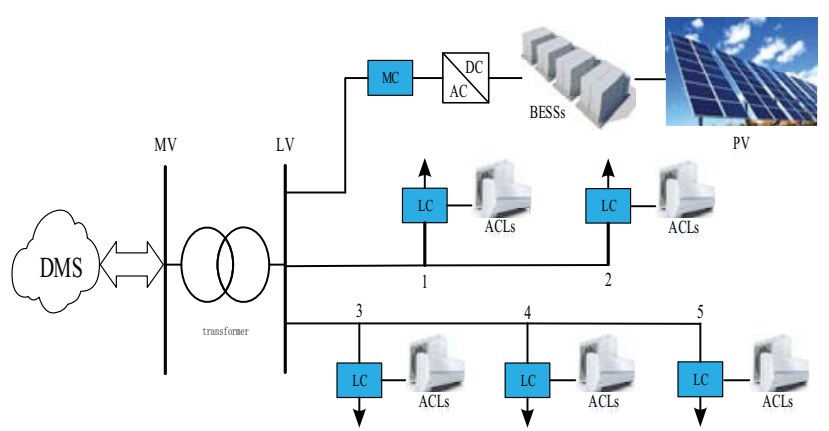

Fig. 3 A five-node radial distribution network configuration
Table 1 Devices' parameters

\begin{tabular}{c|c|c}
\hline$P_{\mathrm{Sr}} / \mathrm{kW}$ & $E_{\text {bess }} / \mathrm{kWh}$ & $P_{\text {bat }}^{\max -\text { discharge }} / \mathrm{kW}$ \\
\hline 10000 & 10000 & 10000 \\
\hline
\end{tabular}

PV generation data is calculated based on the forecasted solar radiation data and the solar PV panels' area. It is assumed that each aggregated ACL group has different building parameters and comfort temperature ranges. Building parameters, temperature ranges and ACL rated powers are shown in Table 2. To simplify the calculation, this paper assumes the same building parameters and thermal comfort within the same ACL group.

Table 2 ACL groups' information

\begin{tabular}{c|c|c|c|c|c|c}
\hline $\begin{array}{c}\text { ACL } \\
\text { Group }\end{array}$ & $\begin{array}{c}\text { Number of houses in } \\
\text { each ACL group }\end{array}$ & $\begin{array}{c}\text { AC rated } \\
\text { power } / \mathrm{kW}\end{array}$ & $\begin{array}{c}\text { House size } \\
\text { (Length/Width/Height) } / \mathrm{m}\end{array}$ & $\begin{array}{c}\text { Wall } \\
\text { Thickness } / \mathrm{m}\end{array}$ & $T_{r}^{\min } /{ }^{\circ} \mathrm{C}$ & $T_{r}^{\max } /{ }^{\circ} \mathrm{C}$ \\
\hline 1 & 400 & 3 & $18 / 12 / 3.2$ & 0.24 & 22 & 27 \\
\hline 2 & 320 & 4 & $20 / 12 / 3.2$ & 0.24 & 23 & 26 \\
\hline 3 & 440 & 2.8 & $15 / 12 / 3.2$ & 0.24 & 22 & 26 \\
\hline 4 & 380 & 4 & $20 / 12 / 3.2$ & 0.24 & 23 & 27 \\
\hline 5 & 350 & 3.5 & $18 / 12 / 3.2$ & 0.24 & 23 & 28 \\
\hline
\end{tabular}

The ambient temperature, solar radiation, electricity purchase price and selling price, for a typical summer day in Foshan City, Guangdong Province, are used in the simulation. As shown in Fig. 4, the meteorological data comes from the China Meteorological Data Website [18], while the electricity price data comes from China Southern Power Grid Company Limited [19]. In order to conveniently test the operation status of air conditioners in a whole day, only summer season data is used here. It should be pointed out that the electricity purchasing price is higher than the selling price. The peak time period for electricity retail price is mainly between 9:0012:00 and 19:00-22:00. The peak time of ambient temperature is mainly between 13:00-17:00.
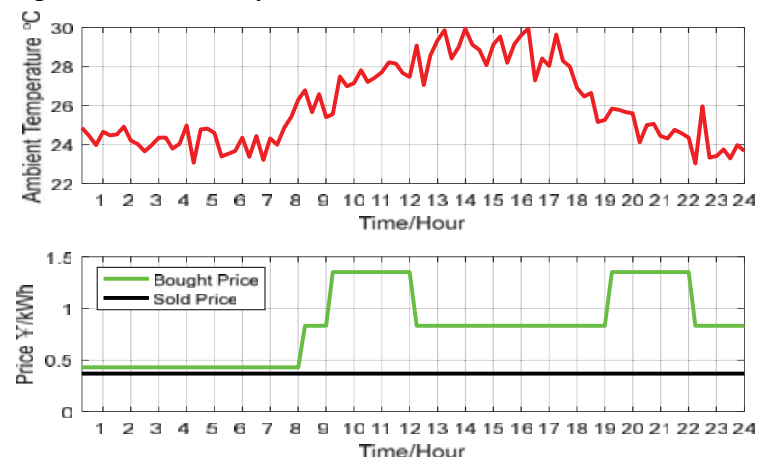

Fig.4 (a) Ambient Temperature (b) Day-ahead Electricity Price

\section{B. Simulation results}

As shown in Fig. 5 and Fig. 6, the expected operation states of ACs and the changes of the internal air temperature of each group within a day are calculated. Since each group has different building parameters and indoor temperature requirements, the operation status of each air conditioner groups in a whole day is different. As seen from Fig. 5, the indoor air temperature of each group is well controlled within the required temperature ranges satisfying the users' thermal comfort. As demonstrated in Fig. 6, the ACs of the five groups are turned on in advance to cool the interior of the building before the peak demand periods occur and are turned off during the peak load periods. The peak demand of the system can be reduced to a lower level by selectively shutting down ACs within a specific period, without affecting the users' thermal comfort.

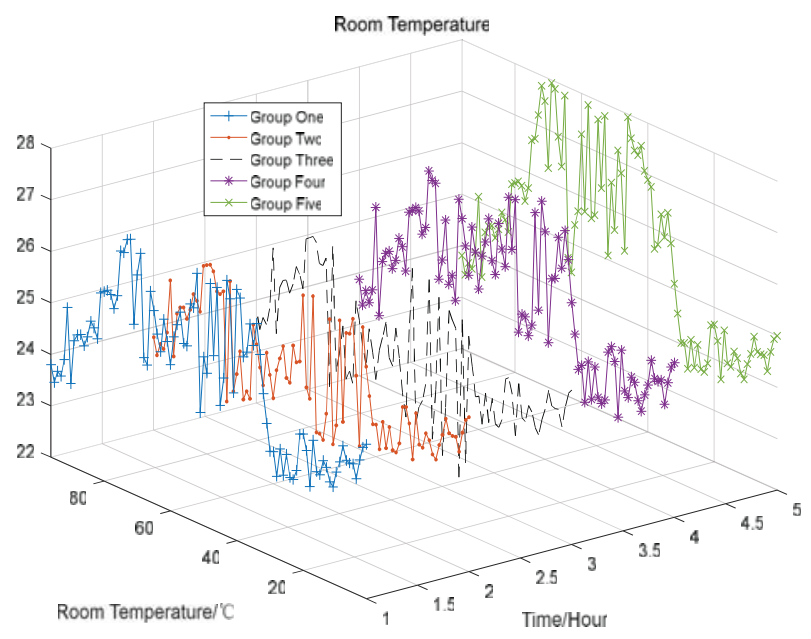

Fig. 5 Internal temperature changes in each group in one day

Fig. 7 reports the variation of the power supplied by the BESS and the corresponding change in the SOC. It can be observed that when the electricity retail prices are high, BESSs discharge power at a high rate (mainly during 9:0015:00 and 19:00-22:00). When the solar radiation is strong 
(mainly at 7:00-17:00), BESSs are charged by the solar PV panels. It is worth noting that during this period, PV power generation is stored by the BESS without any curtailment. Therefore, the control method proposed in this paper can significantly improve the utilization of PV power generation.
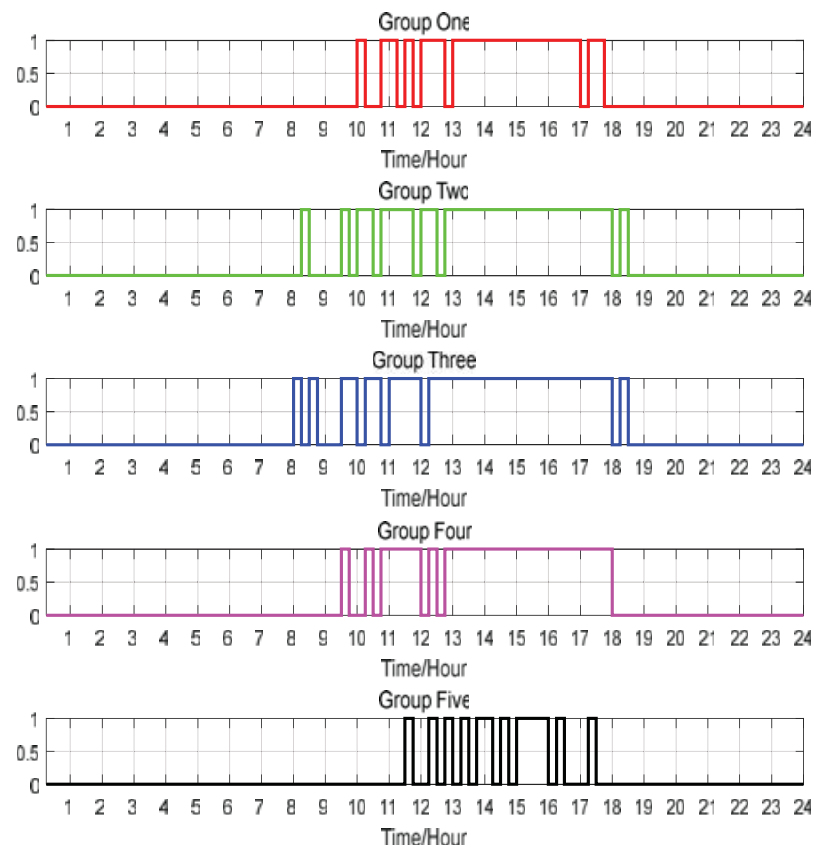

Fig. 6 ACs operation status for each group in one day
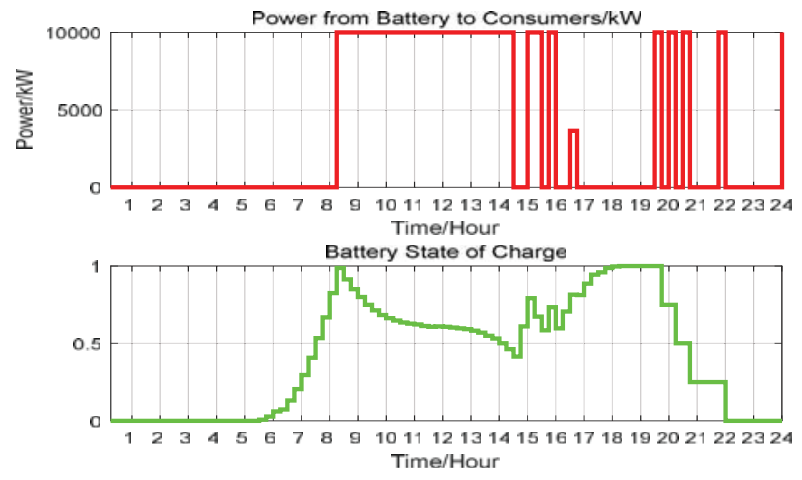

Fig. 7 Operation status of BESS: (a) Power supplied by the BESS (b) Battery SOC

The calculation time of the proposed control scheme is 8.79 seconds under the above operating environment. In order to demonstrate the cost effectiveness of the control scheme proposed in this paper, the system operation cost in this paper is compared with the situation that all the required electricity is bought from the external grid. By consuming the electricity provided by the local distributed solar PV power generation instead of buying electricity from the external grid, the proposed cost is $¥ 277,290$ in one day, which accounts for
$60.4 \%$ of the original system cost $¥ 458,760$.

\section{CONCLUSIONS}

A MILP-based model is proposed to achieve a coordinated control scheme for ACLs, PV and BESS, with objective being to minimize the system operation cost, improve PV generation penetration level, and schedule ACLs without compromising the users' thermal comfort. The simulation is based on a five-node radial distribution network, which attests the feasibility of the proposed scheme. The simulation results prove that the method can minimize the system operation cost while the grid peak demand is lowered and the PV generation utilization rate is increased.

\section{REFERENCES}

[1] Abdmouleh, Zeineb, et al. "Review of optimization techniques applied for the integration of distributed generation from renewable energy sources." Renewable Energy, 113, pp. 266-280, (2017).

[2] Karimi, M., et al. "Photovoltaic penetration issues and impacts in distribution network-A review." Renewable and Sustainable Energy Reviews, 53, pp. 594-605, (2016).

[3] Eftekharnejad, Sara, et al. "Impact of increased penetration of photovoltaic generation on power systems." IEEE Transactions on Power Systems, 28.2, pp. 893-901, (2013).

[4] Wang, Shengwei, and Rui Tang. "Supply-based feedback control strategy of air-conditioning systems for direct load control of buildings responding to urgent requests of smart grids." Applied Energy, 201, pp. 419-432, (2017).

[5] Luo, Fengji, et al. "Optimal dispatch of air conditioner loads in southern China region by direct load control." IEEE Transactions on Smart Grid, 7.1, pp. 439-450, (2016).

[6] Zhang, Wei, et al. "Aggregated modeling and control of air conditioning loads for demand response." IEEE Transactions on Power Systems, 28.4, pp. 4655-4664, (2013).

[7] Bashash, Saeid, and Hosam K. Fathy. "Modeling and control of aggregate air conditioning loads for robust renewable power management." IEEE Transactions on Control Systems Technology, 21.4, pp. 1318-1327, (2013).

[8] Liu, Xiaohu, et al. "Coordinated control of distributed energy storage system with tap changer transformers for voltage rise mitigation under high photovoltaic penetration." IEEE Transactions on Smart Grid, 3.2, pp. 897906, (2012).

[9] Shaojun Huang, J. R. Pillai, M. Liserre and B. Bak-Jensen, "Improving photovoltaic and electric vehicle penetration in distribution grids with smart transformer," IEEE PES ISGT Europe 2013, Lyngby, pp. 1-5, (2013).

[10] Katsanevakis, Markos, Rodney A. Stewart, and Junwei Lu. "Energy storage system utilisation to increase photovoltaic penetration in low voltage distribution feeders." Journal of Energy Storage, 14, pp. 329-347, (2017).

[11] Chaudhary, Priyanka, and M. Rizwan. "Energy management supporting high penetration of solar photovoltaic generation for smart grid using solar forecasts and pumped hydro storage system." Renewable Energy, 118, pp. 928-946, (2018).

[12] Wang, Haiming, et al. "A hierarchical optimization framework for aggregating thermostatically controlled loads to minimize real-time thermal rating of overhead distribution lines." Electricity Distribution (CICED), 2014 China International Conference on. IEEE, 2014.

[13] Massouros, P., G. Athanassouli, and G. Massouros. "A model of the thermal transient state of a wall of a room during the heating by a heating system." International Journal of Energy Research, 24.9, pp. 779-789, (2000).

[14] Bălan, Radu, et al. "Parameter identification and model based predictive control of temperature inside a house." Energy and Buildings, 43.2-3, pp. 748-758, (2011).

[15] Jones, William Peter. Air conditioning engineering. Routledge, 2007. [16] Reddy, S. Surender, P. R. Bijwe, and Abhijit R. Abhyankar. "Real-time economic dispatch considering renewable power generation variability and uncertainty over scheduling period." IEEE Systems Journal, 9.4, pp. 1440- 
1451, (2015).

[17] D. Wang, K. Meng, F. Luo, C. Coates, X. Gao, and Z. Dong, "Coordinated dispatch of networked energy storage systems for loading management in active distribution networks," IET Renewable Power Generation, 10.9, pp. 1374-1381, (2016).

[17] MOSEK. The MOSEK optimization toolbox for MATLAB manual. Version 7.0. Available: http://docs.mosek.com/7.0/toolbox/. (Visited on 1 March 2018)

[18] China Meteorological Data Website. Available: http://data.cma.cn. (Visited on 1 March 2018)

[19] China Southern Power Grid Company Limited. Available: http://www.csg.cn. (Visited on 1 March 2018)

Xueqing Wu male, received the B.Eng. degree in marine and diesel internal combustion from Huazhong Institute of technology and the master's degree in power engineering from Wuhan University of Technology, in 1986 and 1989. He is currently the general manager of Guangdong Foshan Power Construction Corporation Group Co., Ltd., Foshan, China, Whose business scope involves power generation, building materials, data centers, and distributed energy. (E-mail: alexwu@tom.com)

Runji Wu (S'17) male, postgraduate, received the B.Eng. degree in Electrical Engineering and Automation from Guangdong University of Technology, Guangzhou, China. His research interest includes demand side management and renewable energy. (E-mail: holen08@qq.com)

Dongxiao Wang (M'18) male, received the B.Eng. degree in thermal energy and power engineering from North China Electric Power University, Beijing, China, and the Ph.D. degree in electrical engineering from University of Newcastle, Australia, in 2014 and 2018. He is currently a postdoctora research fellow at School of Automation, Guangdong University of Technology, China. His research interest includes demand side management, the utilization of thermostatically controlled loads, energy storage systems, and renewable energy integration. (E-mail: dongxiaouon@gmail.com)

Jinxiao Wei male, received the B.Eng. degree in Telecommunications engineering from Xidian University, Xi'an, China, and the master's degree in control theory and control engineering from University of Science and Technology Liaoning, Liaoning, China, in 2002 and 2008. He is currently working in Guangdong Foshan Power Construction Corporation Group Co., Ltd., Foshan, China, engaged in energy utilization research and development project management. (E-mail: 7950401@qq.com)

Xuecong Li (M'17) male, received the B.Eng. degree in automatic, the master's degree in navigation, guidance and control from Harbin Engineering University, Harbin, China, in 2001 and 2004, and the Ph.D. in control science and engineering from Guangdong University of Technology, Guangzhou, China, in 2014. He is currently the deputy director of the Department of Electrical Engineering at the School of Automation, Guangdong University of Technology. His research interest includes online monitoring of power quality, energy storage systems, renewable energy integration and block chain technology. (E-mail: lixuecong@gdut.edu.cn)

Loi Lei Lai (M'86-SM'92-F'07) received the B.Sc. (first class Hons.) and $\mathrm{Ph}$.D. degrees in electrical and electronic engineering from the University of Aston, Birmingham, U.K., in 1980 and 1984, respectively, and the D.Sc. degree in electrical, electronic, and information engineering from City University London, London, U.K., in 2005 . He is currently a University Distinguished Professor in the Guangdong University of Technology, Guangzhou, China. He was the Director of the Research and Development Centre, Beijing, China, the Pao Yue Kong Chair Professor, the VicePresident, and a Professor and the Chair in electrical engineering for the State Grid Energy Research Institute, Beijing, China; Zhejiang University, Hangzhou, China; IEEE Systems, Man, and Cybernetics Society (IEEE/SMCS), USA; and City University London, respectively. $\mathrm{He}$ conducted high-level consultancy for major international projects such as the Channel Tunnel between U.K. and France. In the last few years, he has given ten keynotes to main international conferences sponsored by the IEEE or the Institution of Engineering and Technology. His research interests are in smart grid, clean energy, and computational intelligence applications in power engineering. Dr. Lai is a Fellow of IET, a Distinguished Expert in the
State Grid Corporation of China, and a National Distinguished Expert in China. He received the IEEE Third Millennium Medal, IEEE Power and Energy Society (IEEE/PES) Power Chapter Outstanding Engineer Award in 2000, IEEE/PES Energy Development and Power Generation Committee Prize Paper in 2006 and 2009, People of the 2012 Scientific Chinese Prize, IEEE/SMCS Outstanding Contribution Award in 2013 and 2014, and is listed in the honor list of the 2014 Thousand Talents Plan, China. (E-mail: 1.1.1ai@ieee.org)

Chun Sing Lai (M'18) male, received a bachelor's degree in electrical and electronic engineering (first class Hons.) from Brunel University, UK, in 2013, and a Ph.D. in engineering science from the University of Oxford, UK. $\mathrm{He}$ is currently an EPSRC researcher at the School of Civil Engineering, University of Leeds, UK, and a visiting researcher at the School of Automation, Guangdong University of Technology, Guangzhou, China. He organized the 2017 IEEE SMC seminar on smart grids and smart cities in Canada. His current research interests are data analysis for renewable energy and energy storage systems, and energy economics. (E-mail: c.s.lai@leeds.ac.uk) 